\title{
Effect of later cord clamping on umbilical cord blood gas in term neonates of diabetic mothers: a randomized clinical trial
}

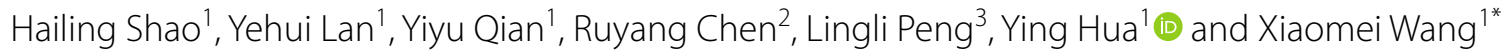

\begin{abstract}
Objective: To evaluate the effect of later cord clamping (LCC) on umbilical arterial blood gas in neonates of diabetic mothers.

Methods: This prospective study included a group of 160 diabetic mothers (DM) whose neonates were randomized to immediate cord clamping (ICC) ( $\leq 15 \mathrm{~s}$ after birth) or LCC ( $\geq 30 \mathrm{~s}$ after birth), and a group of 208 non-diabetic mothers (NDM) whose neonates were randomized to ICC or LCC as a reference. Cord arterial pH, base excess (BE), bicarbonate $\left(\mathrm{HCO}_{3}{ }^{-}\right)$, partial pressure of carbon dioxide $\left(\mathrm{pCO}_{2}\right)$, partial pressure of oxygen $\left(\mathrm{pO}_{2}\right)$, lactate, hemoglobin, hematocrit and glucose were compared among groups.

Results: In neonates of DM, there was no significant difference in cord arterial pH between the ICC and LCC group. $\mathrm{LCC}$ of $\geq 30 \mathrm{~s}$ decreased umbilical arterial $\mathrm{HCO}_{3}{ }^{-}$and $\mathrm{BE}$ and increased lactate (ICC versus $\mathrm{LCC}, \mathrm{HCO}_{3}{ }^{-}: 24.3$ $(22.7,25.8)$ versus $23.7(22.3,24.7) \mathrm{mmol} / \mathrm{L}, P=0.01 ; \mathrm{BE}:-2.70(-4.80,-1.50)$ versus $-3.72(-5.66,-2.36) \mathrm{mmol} / \mathrm{L}, P=0.006$; lactate: $2.1(1.6,3.7)$ versus $2.7(2.1,4.3) \mathrm{mmol} / \mathrm{L}, P=0.005)$, without the alterations of $\mathrm{pCO}_{2}, \mathrm{pO}_{2}$, hemoglobin, hematocrit and glucose. Similar results were found in neonates of NDM (ICC versus $\mathrm{LCC}, \mathrm{HCO}_{3}^{-}: 24.3(23.1,25.7)$ versus 23.5 $(22.3,24.8) \mathrm{mmol} / \mathrm{L}, P=0.01$; BE: $-2.39(-3.73,-1.51)$ versus $-3.40(-4.73,-1.91) \mathrm{mmol} / \mathrm{L}, P=0.001$; lactate: $2.2(1.9,3.3)$ versus $2.5(2.0,4.3) \mathrm{mmol} / \mathrm{L}, P=0.01)$, except for the higher level of hemoglobin in the LCC group. The majority of diabetic mothers (ICC: 92.0\%; LCC: $91.8 \%$ ) had good blood glucose control. No differences were observed in acid-base status and glucose between neonates of DM and neonates of NDM in both ICC and LCC, but hemoglobin and hematocrit were elevated after ICC in neonates of DM compared to neonates of NDM.
\end{abstract}

Conclusions: Later cord clamping of $\geq 30$ s resulted in a tendency towards metabolic acidosis of umbilical arterial blood in neonates of DM and NDM. Umbilical arterial blood gas parameters at birth were similar in neonates of DM and NDM.

Trial registration: ClinicalTrials.gov: NCT04369313; date of registration: 30/04/2020 (retrospectively registered).

Keywords: Later cord clamping, Diabetic pregnancy, Umbilical cord blood gas

\footnotetext{
*Correspondence: wangxiaomei12321@163.com

1 Department of Obstetrics and Gynecology, the Second Affiliated

Hospital of Wenzhou Medical University, 325027 Wenzhou, China

Full list of author information is available at the end of the article
}

\section{Background}

Umbilical cord blood gas analysis, a valuable and reliable method, is used for assessing the acid-base status of neonates [1-3]. Umbilical artery carries blood from fetus to placenta, thus umbilical arterial blood gas is more reflective of the fetus status, which is widely recommended in high-risk deliveries [1]. Umbilical arterial blood gas 
analysis is an essential criterion for neonatal hypoxic ischemic encephalopathy [4]. Neonates with 5-minute Apgar scores of $\geq 7$, umbilical artery $\mathrm{pH} \leq 7.00$ combined with $\mathrm{BE} \geq 12 \mathrm{mmol} / \mathrm{L}$ were more likely to develop respiratory distress syndrome (RDS) [5].

The American College of Obstetricians and Gynecologists (ACOG) recommended a delay of cord clamping for at least 30-60 s (s) in neonates, because it improved hemoglobin levels and iron stores [6]. To date, several studies had investigated the influence of later cord clamping (LCC) on umbilical cord blood gas in low-risk pregnancy. LCC led to a tendency of acidemia in umbilical cord blood, presenting as decreased $\mathrm{pH}$, base excess (BE) and bicarbonate $\left(\mathrm{HCO}_{3}{ }^{-}\right)$and increased lactate and partial pressure of carbon dioxide $\left(\mathrm{pCO}_{2}\right)$ [7-9]. In contrast, several studies demonstrated that arterial and venous cord blood $\mathrm{pH}$ was unaffected after LCC [10-12].

Pregnancy complicated with diabetes mellitus is associated with short-term adverse implications of neonates, including respiratory distress syndrome, hypoglycemia, polycythemia, hyperbilirubinemia, and even perinatal death [13]. Due to fetal hyperinsulinemia and subsequent lung surfactant synthesis, neonates of diabetic mothers (DM) are more susceptible to intrapartum hypoxia [13]. A retrospective study showed that, under the condition of non-reassuring fetal heart rate, umbilical arterial blood $\mathrm{pH}$ decreased by 0.035 (7.250-7.215) in neonates of DM than that in neonates of non-diabetic mothers (NDM) [14]. Besides, compared with healthy newborns, neonates of DM were at an approximately five-fold risk of admission to intensive care unit and a 2-9 fold risk of 5-min Apgar score of $<7[15,16]$.

Currently, no studies have described the effect of LCC on umbilical cord blood gas in neonates of diabetic mothers. The prevalence of gestational diabetes mellitus has been on the rise in recent years. Therefore, in this study, we identified the changes of umbilical arterial blood gas and hematological parameters following LCC of $\geq 30 \mathrm{~s}$ in neonates of DM and NDM without the need for immediate resuscitation.

\section{Methods}

This was a prospective study conducted in the Second Affiliated Hospital of Wenzhou Medical University from September 2019 to September 2020 (clinicaltrials.gov: NCT04369313, ClinicalTrials.gov: NCT04369313; date of registration: 30/04/2020). This study was supported by the Research Ethics Committee of our hospital (approval number: L-2019-13). Pregnant women all signed written informed consent before delivery. Delayed cord clamping was introduced in this hospital in 2017. In this study, the clamping time in the immediate cord clamping (ICC) group was less than $15 \mathrm{~s}$ after birth, and it was more than $30 \mathrm{~s}$ in the LCC group.

All diabetic mothers with a singleton pregnancy at term were screened for eligibility when they were admitted into our hospital for vaginal delivery or selective cesarean section. Pregnancy complicated with diabetes included gestational diabetes mellitus (GDM) and pregestational diabetes mellitus (PGDM). GDM was screened by $75 \mathrm{~g}$ oral glucose tolerance test (OGTT) at 24-28 weeks of gestation. Fasting plasma glucose (FPG) $\geq 5.1$ $\mathrm{mmol} / \mathrm{L}$, or $1 \mathrm{~h} \mathrm{(h)} \mathrm{plasma} \mathrm{glucose} \geq 10.0 \mathrm{mmol} / \mathrm{L}$, or $2 \mathrm{~h}$ plasma glucose $\geq 8.5 \mathrm{mmol} / \mathrm{L}$ was diagnostic criteria for GDM. Women at high risk for diabetes were tested for $\mathrm{FPG}$ and $\mathrm{HbA} 1 \mathrm{C}$ at the first prenatal visit. $\mathrm{FPG} \geq 7.0$ $\mathrm{mmol} / \mathrm{L}$ or $\mathrm{HbA} 1 \mathrm{C} \geq 6.5 \%$ was considered as PGDM. Well-controlled blood glucose was defined as an HbA1C level $<6.0 \%$ in late pregnancy. Mothers with other pregnancy complications (hypertension disorders, intrahepatic cholestasis of pregnancy, maternal fever, multiple pregnancy, preterm labor, post-term pregnancy, emergency cesarean section, abnormal fetal presentation) and the neonates with birth weight $<2500 \mathrm{~g}$, Apgar score of $\leq 7$, neonatal malformation, suspicious fetal distress, neonatal resuscitation were all excluded. In addition, mothers were withdrawn from the study if cord blood collection failed and blood gas parameters were missed. Non-diabetic mothers at term were also recruited consecutively.

Diabetic women were randomly assigned to ICC or LCC at a ratio of $1: 1$, by using a random number sequence generator. Opaque envelopes with an A card or a B card inside were pre-prepared and then arranged according to the random sequence. The women who drew the A card were assigned to the ICC group, and the women who drew the $\mathrm{B}$ card were assigned to the LCC group. Nondiabetic mothers were also randomized according to the method above.

Because the procedure of umbilical cord clamping was carried out by researchers and mothers were always clearly conscious, the group allocation was not possible to be masked to the mothers, the researchers performing the intervention and the assistant recording the clamping time. However, the staff responsible for the blood gas analysis and data collection was blind to patient's allocation.

Before the cord was clamped, neonates with vaginal delivery were placed on the abdomen of mothers, and neonates with cesarean section were placed between the legs of mothers. The clamping time of each group was recorded by an assistant. The trial should be discontinued immediately if any rescue intervention was required for neonates or mothers. 
Three vascular forceps were used to clamp the umbilical cord. The first forcep was placed at the unbilical cord $5 \mathrm{~cm}$ from the fetal side, the second forcep was at $5-10 \mathrm{~cm}$ from the first forcep, and the third forcep was at the umbilical cord $10 \mathrm{~cm}$ from the placenta. The umbilical cord was cut between the first and the second vascular forceps. At least $0.5 \mathrm{ml}$ of umbilical arterial blood was extracted between the second and the third vascular forceps by a pre-heparinized syringe. Blood gas analysis and the test of hemoglobin $(\mathrm{Hb})$, hematocrit (Hct) and glucose in umbilical arterial blood were performed using the automated blood gas analyser (Cobas b 123, Roche) within $15 \mathrm{~min}$.

According to the previous study, umbilical arterial blood $\mathrm{pH}$ was $7.28 \pm 0.07$ [12]. A sample size of 66 in each group achieved $90 \%$ power to detect a 0.04 decrease of arterial $\mathrm{pH}$ in the DCC group with a two-sided significance level of 0.05 . Considering that unqualified cases needed to be excluded from the trial, we increased the number of cases in NP groups to 130 and DP groups to 90. The primary outcome was the change of umbilical cord arterial $\mathrm{pH}$. The secondary outcomes were $\mathrm{HCO}_{3}{ }^{-}$, $\mathrm{BE}$, lactate, partial pressure of oxygen $\left(\mathrm{pO}_{2}\right)$ and $\mathrm{pCO}_{2}$ of umbilical arterial blood, neonatal hemoglobin $(\mathrm{Hb})$, hematocrit (Hct) and blood glucose.

The data were analyzed by SPSS 25.0 software. The comparisons of continuous variables with normal distributions (mean \pm standard deviation) were conducted by Student $\mathrm{t}$-test or one-way ANOVA. Mann-Whitney U test was used to compare continuous variables without normal distribution (median with interquartile range), and Pearson's Chi-square test was used to compare categorical variables. A two-sided $P$-value $<0.05$ meaned statistically significant.

\section{Results}

One thousand ninety-six pregnant women were assessed for eligibility from September 2019 to September 2020, 597 of whom were excluded for not meeting the inclusion criteria and 58 of whom declined to participate in this study. Then, 441 pregnant women were enrolled, of whom 73 pregnancies were excluded from the analysis. Finally, among diabetic mothers, 87 cases received ICC and 73 cases received LCC, and among non-diabetic mothers, 101 cases received ICC and 107 cases received LCC (Fig. 1).

As shown in Table 1, no differences were found in the demographic characteristics of mothers and neonates among the four groups. The majority of diabetic mothers had good blood glucose control (ICC: $92.0 \%$; LCC: 91.8\%). The median clamping time was $6 \mathrm{~s}$ in DM (ICC) and $44 \mathrm{~s}$ in DM (LCC), $6 \mathrm{~s}$ in NDM (ICC), and $45 \mathrm{~s}$ in NDM (LCC), respectively (Table 2).

\section{LCC versus ICC in neonates of diabetic mothers}

In comparison with ICC, the umbilical arterial blood $\mathrm{HCO}_{3}{ }^{-}$and $\mathrm{BE}$ decreased markedly in LCC, while the lactate level increased (LCC versus ICC, $\mathrm{HCO}_{3}{ }^{-}: 24.3$ (22.7, 25.8) versus $23.7(22.3,24.7) \mathrm{mmol} / \mathrm{L} ; \mathrm{BE}:-2.70$ $(-4.80,-1.50)$ versus $-3.72(-5.66,-2.36) \mathrm{mmol} / \mathrm{L}$; lactate: $2.1(1.6,3.7)$ versus $2.7(2.1,4.3) \mathrm{mmol} / \mathrm{L})$. Other umbilical arterial blood gas parameters $\left(\mathrm{pH}, \mathrm{pCO}_{2}, \mathrm{pO}_{2}, \mathrm{Hb}\right.$, Hct and glucose) did not differ significantly between LCC and ICC (Table 2).

\section{LCC versus ICC in neonates of non-diabetic mothers}

Comparisons of umbilical arterial blood gas parameters in $\mathrm{NDM}$ showed that $\mathrm{HCO}_{3}{ }^{-}$and $\mathrm{BE}$ were significantly decreased, but lactate and $\mathrm{Hb}$ were markedly increased in the LCC group (ICC versus $\mathrm{LCC}, \mathrm{HCO}_{3}^{-}: 24.3$ (23.1, $25.7)$ versus $23.5(22.3,24.8) \mathrm{mmol} / \mathrm{L} ; \mathrm{BE}:-2.39(-3.73$, $-1.51)$ versus $-3.40(-4.73,-1.91) \mathrm{mmol} / \mathrm{L}$; lactate: 2.2 $(1.9,3.3)$ versus $2.5(2.0,4.3) \mathrm{mmol} / \mathrm{L} ; \mathrm{Hb}: 14.6$ (13.9, $15.4)$ versus $14.9(13.9,16.3) \mathrm{g} / \mathrm{dl} ; P<0.05)$. No differences were found in $\mathrm{pH}, \mathrm{pCO}_{2}, \mathrm{pO}_{2}$, Hct and glucose between two groups (Table 2).

\section{Non-diabetic mothers versus diabetic mothers in ICC or LCC}

There were no differences in acid-base status and glucose of umbilical arterial blood between the two groups in both ICC and LCC. Among the neonates received ICC, the $\mathrm{Hb}$ and Hct levels were obviously higher in DM group than those in NDM group (DM versus NDM, $\mathrm{Hb}$ : $15.2(14.0,16.1)$ versus $14.6(13.9,15.4) \mathrm{g} / \mathrm{dl}, P=0.007$; Hct: $44.0(39.8,47.6)$ versus $42.5(39.9,44.8) \%, P=0.02)$. However, the differences disappeared among neonates who received LCC.

\section{Discussion}

Our study showed significant alterations of partial umbilical arterial blood gas parameters both in neonates with non-diabetic mothers and diabetic mothers after a delay of cord clamping more than $30 \mathrm{~s}$ after birth. Later cord clamping of $\geq 30 \mathrm{~s}$ was associated with reduced $\mathrm{HCO}_{3}{ }^{-}$ and $\mathrm{BE}$ and increased lactate, without variations in arterial $\mathrm{pH}, \mathrm{pCO}_{2}$ and $\mathrm{pO}_{2}$, suggesting a tendency towards metabolic acidosis. Umbilical arterial blood acid-base state in DM was similar with that in NDM both in ICC group and LCC group. $\mathrm{Hb}$ and Hct levels in umbilical arterial blood were higher in DM group than those in NDM group when the neonates received ICC rather than LCC.

Two prospective observational studies used blood samples from unclamped umbilical cords to investigate umbilical cord blood gas at different time points after birth in 


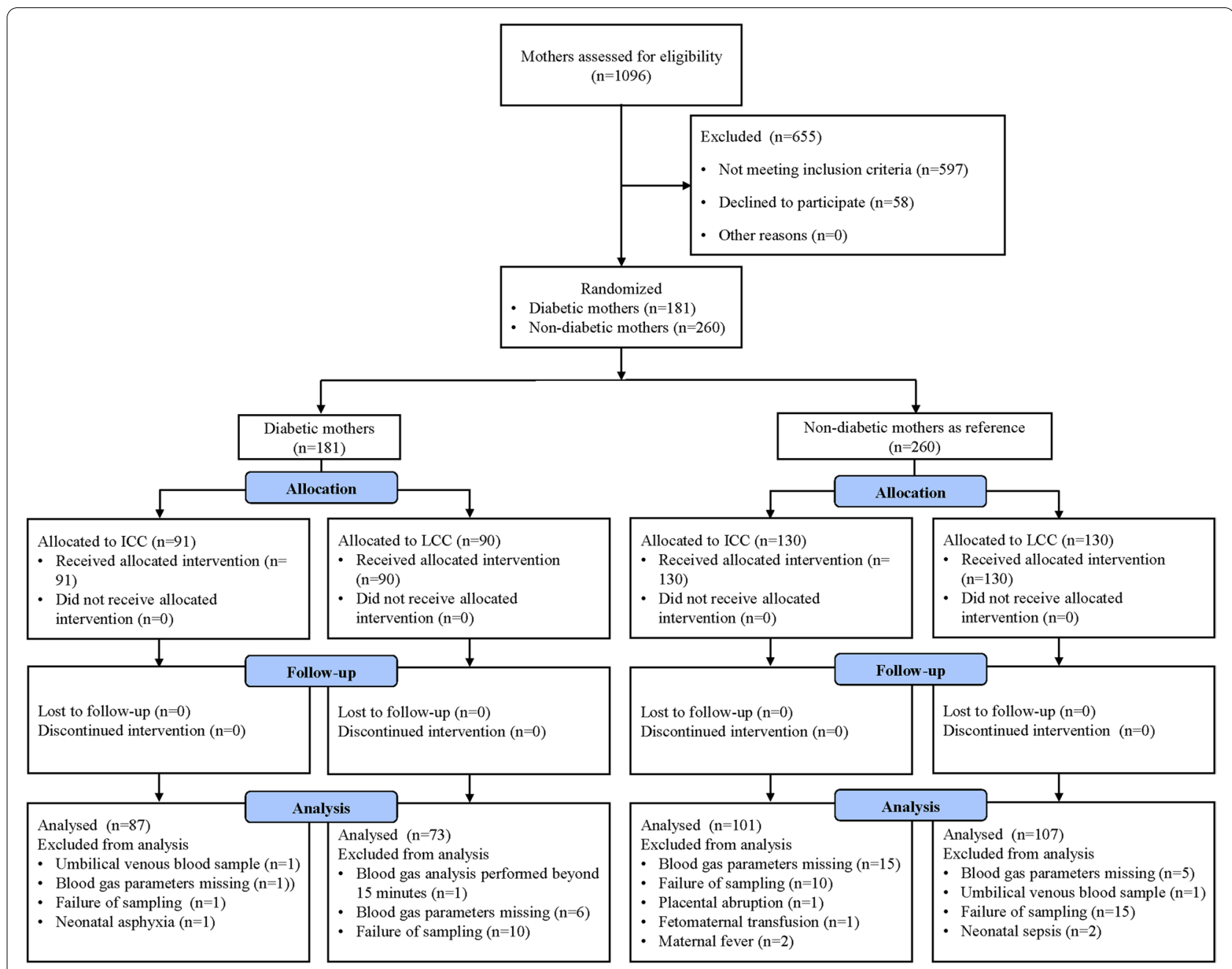

Fig. 1 Study flow chart

healthy full-term newborns [7, 9]. Wiberg et al. enrolled 66 neonates delivered vaginally and found that there was a trend of mixed acidosis in umbilical artery $\left(\mathrm{pH}, \mathrm{HCO}_{3}{ }^{-}\right.$ and $\mathrm{BE}$ decreased, and $\mathrm{pCO}_{2}, \mathrm{pO}_{2}$ and lactate increased) from birth to $90 \mathrm{~s}$ of life, with the most obvious changes in the first $45 \mathrm{~s}$ [7]. Another study showed that 3-minute LCC also resulted in decreased $\mathrm{pH}, \mathrm{HCO}_{3}{ }^{-}$and $\mathrm{BE}$ and increased $\mathrm{pCO}_{2}, \mathrm{pO}_{2}$ and lactate during cesarean section, and similar changes during vaginal delivery except for $\mathrm{pCO}_{2}$ [9]. Likewise, we found that $\mathrm{HCO}_{3}{ }^{-}$and $\mathrm{BE}$ were higher and lactate was lower after LCC of more than $30 \mathrm{~s}$ in both NDM and DM group, but there was no change in arterial $\mathrm{pH}$ and $\mathrm{CO}_{2}$. It might be related to different methods of sampling (samples from an unclamped cord versus samples from a double clamped cord).

Factors including the position of fetus, delivery mode, anesthesia method could influence cord gas parameters [2]. Selective cesarean section led to increased $\mathrm{pH}, \mathrm{BE}$, $\mathrm{HCO}_{3}{ }^{-}$and $\mathrm{pO}_{2}$, and reduced $\mathrm{pCO}_{2}$, similar to adult blood gas values [17]. Spinal anesthesia was thought to increase the risk of cord acidemia [18]. In this study, all neonates were in vertex presentation, and all mothers received epidural anesthesia in cesarean section or received epidural labor analgesia during vaginal delivery. The ratio between vaginal delivery and cesarean section was similar in each group. Thus, cord gas parameters were comparable among groups.

Hidden acidosis might account for the umbilical arterial acid-base imbalance both in NDM and DM after later cord clamping. During cesarean section, both blood obstruction in the inferior vena cava caused by maternal supine position and anesthesia resulted in placental hypoperfusion $[19,20]$. During vaginal delivery, uterine contraction intermittently interrupted the utero-placental circulation. These led to transient fetal hypoxia. Blood transported into central organs in priority, and peripheral organs with reduced blood supply underwent anaerobic metabolism, a phenomenon 
Table 1 Demographic characteristics of mothers and neonates

\begin{tabular}{|c|c|c|c|c|c|}
\hline & \multicolumn{2}{|l|}{ DM } & \multicolumn{2}{|l|}{ NDM } & \multirow[t]{2}{*}{$P^{*}$} \\
\hline & $\begin{array}{l}\text { ICC } \\
N=87\end{array}$ & $\begin{array}{l}\mathrm{LCC} \\
N=73\end{array}$ & $\begin{array}{l}\text { ICC } \\
N=101\end{array}$ & $\begin{array}{l}\text { LCC } \\
N=107\end{array}$ & \\
\hline \multicolumn{6}{|l|}{ Mothers } \\
\hline Age (years) & $31.0 \pm 3.9$ & $30.5 \pm 4.9$ & $29.7 \pm 5.2$ & $30.2 \pm 4.4$ & 0.30 \\
\hline BMI $\left(\mathrm{Kg} / \mathrm{m}^{2}\right)$ & $27.2 \pm 3.4$ & $27.1 \pm 3.0$ & $27.1 \pm 3.6$ & $26.4 \pm 2.7$ & 0.31 \\
\hline Prenatal $\mathrm{Hb}(\mathrm{g} / \mathrm{L})$ & $119.5 \pm 11.2$ & $121.0 \pm 12.0$ & $117.9 \pm 11.4$ & $119.3 \pm 11.7$ & 0.38 \\
\hline \multicolumn{6}{|l|}{$\begin{array}{l}\text { Blood glu- } \\
\text { cose control, } \\
\text { n (\%) }\end{array}$} \\
\hline Well-controlled & $80(92.0)$ & $67(91.8)$ & - & - & $0.97^{\mathrm{a}}$ \\
\hline Poorly-controlled & $7(8.0)$ & $6(8.2)$ & - & - & \\
\hline \multicolumn{6}{|l|}{ Neonates } \\
\hline $\begin{array}{l}\text { Gestational age } \\
\text { (weeks) }\end{array}$ & $38.8 \pm 0.8$ & $39.0 \pm 1.0$ & $39.0 \pm 0.8$ & $39.0 \pm 0.9$ & 0.52 \\
\hline \multicolumn{6}{|l|}{$\begin{array}{l}\text { Delivery method, } \\
\text { n (\%) }\end{array}$} \\
\hline Vaginal delivery & $32(36.8)$ & $31(42.5)$ & $32(31.7)$ & $33(30.8)$ & 0.36 \\
\hline Cesarean section & $55(63.2)$ & $42(57.5)$ & $69(68.3)$ & $74(69.2)$ & \\
\hline \multicolumn{6}{|c|}{ Neonatal sex, n (\%) } \\
\hline Male & $49(56.3)$ & $37(50.7)$ & $44(43.6)$ & $60(56.1)$ & 0.24 \\
\hline Female & $38(43.7)$ & $36(49.3)$ & $57(56.4)$ & $47(43.9)$ & \\
\hline Birthweight (g) & $3321.9 \pm 394.9$ & $3394.1 \pm 413.0$ & $3290.5 \pm 361.2$ & $3378.4 \pm 374.0$ & 0.23 \\
\hline Body length (cm) & $50(49,50)$ & $50(50,50)$ & $50(49,50)$ & $50(49,50)$ & 0.26 \\
\hline $\begin{array}{l}\text { 1-min Apgar } \\
\text { score }\end{array}$ & $10(10,10)$ & $10(10,10)$ & $10(10,10)$ & $10(10,10)$ & 0.32 \\
\hline $\begin{array}{l}\text { 5-min Apgar } \\
\text { score }\end{array}$ & $10(10,10)$ & $10(10,10)$ & $10(10,10)$ & $10(10,10)$ & 0.79 \\
\hline
\end{tabular}

NDM non-diabetic mothers, DM diabetic mothers, ICC immediate cord clamping, LCC later cord clamping

$B M I$ body mass index, $\mathrm{Hb}$ hemoglobin

Data were given as mean $\pm \mathrm{SD}, \mathrm{n}(\%)$ or median (IQR)

* Chi-square test for categorical variables, Mann-Whitney U-test or student t-test for quantitative variables; the comparisons were conducted among four groups

a The comparisons were conducted between ICC and LCC from DM

known as "hidden acidosis". LCC carried more blood to neonates, peripheral organs were preferentially perfused, and acid metabolites were released into circulation [21], which might be the reason for the detected increased lactate and decreased $\mathrm{HCO}_{3}{ }^{-}$and $\mathrm{BE}$ in our study.

The lung perfusion increases from 8 to $45 \%$ of the cardiac output immediately after birth [22]. After the establishment of effective lung ventilation, $\mathrm{CO}_{2}$, as volatile acid, can decrease rapidly. In contrast, the fixed acids continue to accumulate, resulting in decreasing bicarbonate and $\mathrm{BE}$ [7]. In our study, neonates with LCC of $\geq 30 \mathrm{~s}$ already had adequate lung ventilation, enabling $\mathrm{CO}_{2}$ to transport quickly out of the body. Thus, we observed an increase in lactate, which led to a decrease in $\mathrm{HCO}_{3}{ }^{-}$and $\mathrm{BE}$. But $\mathrm{CO}_{2}$ remained at the same level as the neonates who received ICC.
Base excess, rather than $\mathrm{pH}$, is an ideal indicator of the degree of hypoxia. BE depends linearly on the accumulation of metabolic acid, while large changes in hydrogen ion concentration are manifested only by small changes in $\mathrm{pH}$. Lactate detected in umbilical cord blood comes almost entirely from the fetus [2]. Thus, lactate and BE are more appropriate indexes to evaluate neonatal acid-base status. Alterations in blood gas combined with abnormal symptoms such as low Apgar score could provide more reliable evidence in predicting adverse perinatal outcomes [2]. Whereas, for ethical reasons, we enrolled neonates with Apgar score of $>7$ who did not require immediate resuscitation for implementing LCC. Hence, our findings of decreased BE and increased lactate after LCC of $\geq 30$ s seemed to have no significance in predicting the prognosis of neonates.

The effect of LCC on umbilical arterial $\mathrm{pO}_{2}$ remained inconclusive. De Paco et al. and Andersson et al. 
Table 2 Comparisons of umbilical arterial blood gas analysis between groups

\begin{tabular}{|c|c|c|c|c|c|c|c|c|}
\hline & \multicolumn{2}{|l|}{ DM } & \multicolumn{2}{|l|}{ NDM } & \multirow{2}{*}{$\begin{array}{l}\text { DM } \\
P^{*}\end{array}$} & \multirow[t]{2}{*}{ NDM } & \multicolumn{2}{|l|}{$\begin{array}{l}\text { DM vs } \\
\text { NDM }\end{array}$} \\
\hline & \multirow{2}{*}{$\begin{array}{l}\text { ICC } \\
N=87\end{array}$} & \multirow{2}{*}{$\begin{array}{l}\mathrm{LCC} \\
N=73\end{array}$} & \multirow{2}{*}{$\begin{array}{l}\text { ICC } \\
N=101\end{array}$} & \multirow{2}{*}{$\begin{array}{l}\text { LCC } \\
N=107\end{array}$} & & & & \\
\hline & & & & & ICC vs LCC & ICC vs LCC & ICC & LCC \\
\hline $\begin{array}{l}\text { Cord clamping time (sec- } \\
\text { onds) }\end{array}$ & $6(4,9)$ & $44(37,55)$ & $6(4,9)$ & $45(38,56)$ & $<0.001$ & $<0.001$ & 0.82 & 0.83 \\
\hline $\mathrm{pH}$ & $7.309(7.255,7.330)$ & $7.303(7.245,7.328)$ & $7.303(7.280,7.327)$ & $7.305(7.273,7.322)$ & 0.41 & 0.37 & 0.74 & 0.89 \\
\hline $\mathrm{pCO}_{2}(\mathrm{mmHg})$ & $50.1(45.8,54.1)$ & $49.2(45.7,55.3)$ & $49.5(47.4,53.8)$ & $49.5(45.2,54.3)$ & 0.32 & 0.42 & 0.89 & 0.84 \\
\hline $\mathrm{pO}_{2}(\mathrm{mmHg})$ & $19.8(17.0,23.2)$ & $21.1(17.1,24.1)$ & $19.1(16.0,24.1)$ & $20.4(16.5,24.5)$ & 0.25 & 0.30 & 0.92 & 0.85 \\
\hline $\mathrm{HCO}_{3}^{-}(\mathrm{mmol} / \mathrm{L})$ & $24.3(22.7,25.8)$ & $23.7(22.3,24.7)$ & $24.3(23.1,25.7)$ & $23.5(22.3,24.8)$ & 0.01 & 0.01 & 0.87 & 0.74 \\
\hline $\mathrm{BE}(\mathrm{mmol} / \mathrm{L})$ & $-2.70(-4.80,-1.50)$ & $-3.72(-5.66,-2.36)$ & $-2.39(-3.73,-1.51)$ & $-3.40(-4.73,-1.91)$ & 0.006 & 0.001 & 0.22 & 0.08 \\
\hline Lactate (mmol/l) & $2.1(1.6,3.7)$ & $2.7(2.1,4.3)$ & $2.2(1.9,3.3)$ & $2.5(2.0,4.3)$ & 0.005 & 0.01 & 0.61 & 0.55 \\
\hline $\mathrm{Hb}(\mathrm{g} / \mathrm{dl})$ & $15.2(14.0,16.1)$ & $15.4(14.4,16.4)$ & $14.6(13.9,15.4)$ & $14.9(13.9,16.3)$ & 0.43 & 0.02 & 0.007 & 0.33 \\
\hline Hct (\%) & $44.0(39.8,47.6)$ & $44.8(41.0,48.6)$ & $42.5(39.9,44.8)$ & $43.1(40.1,47.3)$ & 0.20 & 0.06 & 0.02 & 0.09 \\
\hline Glucose (mmol/L) & $3.8(3.4,4.7)$ & $3.8(3.3,4.8)$ & $3.7(3.4,4.6)$ & $3.6(3.2,4.4)$ & 0.85 & 0.35 & 0.62 & 0.16 \\
\hline
\end{tabular}

NDM non-diabetic mothers, DM diabetic mothers, ICC immediate cord clamping, LCC later cord clamping

* Mann-Whitney U-test for quantitative variables

demonstrated that LCC increased umbilical arterial $\mathrm{pO}_{2}$ because of a continuing supply of oxygen $[10,11]$. However, $\mathrm{pO}_{2}$ was not affected in another study [12]. Our study revealed a slight non-significant increase in $\mathrm{pO}_{2}$ after LCC of $\geq 30 \mathrm{~s}$ compared with ECC (The median clamping time: $6 \mathrm{~s}$ ) in both NDM and DM. This may be related to the fact that most neonates were able to establish good ventilation immediately after birth. In addition, neonates of DM are at increased risk of transient shortness of breath [13]. The increase in $\mathrm{pO}_{2}$ caused by LCC was offset by the decrease in $\mathrm{pO}_{2}$ caused by abnormal pulmonary ventilation in neonates of DM [13].

Neonates of insulin-dependent diabetic mothers were at high risk of perinatal asphyxia. Analysis of umbilical blood samples from neonates of type 1 diabetic mothers in later pregnancy showed acidosis and hyperlacticaemia, without hypoxemia [23]. Intrauterine fetal death in diabetic mothers might be due to metabolic acidosis, rather than hypoxia [23], because fetal hyperglycemia and subsequent hyperinsulinemia caused by maternal hyperglycemia could increase metabolic activity and lactic acid accumulation in the body of the fetus. Our data showed that compared with neonates of NDM, neonates of DM had no change in umbilical cord blood gas parameters, whether they received ICC or LCC. This might be because the blood glucose was well-controlled through diet alone in most diabetic mothers and the umbilical artery blood glucose levels at birth were similar in NDM and DM in this study. Another reason was that neonates with suspicious fetal distress and Apgar score of $\leq 7$ were excluded.
Gestational diabetes is associated with neonatal polycythemia [24-26], possibly due to elevated insulin and erythropoietin [13]. This study was the first to use umbilical cord blood gas to find an increase in hematocrit and hemoglobin in neonates of DM after ICC. However, after LCC, there were no differences in hematocrit and hemoglobin between neonates of NDM and DM, possibly because LCC delivered more blood to neonates, thereby eliminating these differences.

In this study, hemoglobin, hematocrit and glucose levels were tested in umbilical cord blood. Previous studies found that hemoglobin and hematocrit were higher in neonatal blood than those in umbilical cord blood after birth [27], and plasma glucose was lower [28]. Despite of these differences, three indexes in cord blood were all positively correlated with those in neonatal blood $[27,28]$. Thus, the umbilical cord blood could be alternative in exploring neonatal hematologic status.

This study was the first one to report on umbilical arterial blood gas in neonates of diabetic mothers at cord clamping $\geq 30 \mathrm{~s}$. We found that the acid-base status of neonates of DM was similar to that of the healthy neonates of NDM at birth. A delay of cord clamping for $\geq 30 \mathrm{~s}$ was associated with a tendency towards metabolic acidosis in neonates of DM. In clinical practice including vaginal delivery and cesarean section, for neonates of diabetic mothers without the need for immediate resuscitation, especially those whose mothers have wellcontrolled blood glucose during pregnancy, cord clamping $\geq 30 \mathrm{~s}$ could be adopted. Whereas, several limitations should be considered in our study. First, we merely explored the effect of LCC on umbilical cord blood gas 
without exploring the safety of LCC, such as neonatal bilirubin and phototherapy rate. Second, most mothers in our study were with well-controlled blood glucose. Further studies focusing on insulin-dependent mothers are needed. Third, partial cases with blood gas parameters missing led to an inevitable bias. Lastly, this study examined LCC for just $30 \mathrm{~s}$ or more and not for longer periods.

In summary, cord clamping $\geq 30 \mathrm{~s}$ was associated with a trend of metabolic acidosis in umbilical arterial blood both in neonates of diabetic mothers and non-diabetic mothers, most likely due to "hidden acidosis". Umbilical arterial blood gas parameters at birth were similar in DM and NDM.

\section{Abbreviations}

BE: Base excess; DM: Diabetic mothers; $\mathrm{HCO}_{3}$ : Bicarbonate; ICC: Immediate cord clamping; LCC: Later cord clamping; NDM: Non-diabetic mothers; $\mathrm{pCO}_{2}$ : Partial pressure of carbon dioxide; $\mathrm{pO}_{2}$ : Partial pressure of oxygen.

\section{Acknowledgements}

We would like to thank all the authors' work and the financial support by grants from Lin He's Academician Workstation of New Medicine and Clinical Translation and the Obstetrics and gynecology of combine traditional Chinese and Western medicine of Zhejiang Province.

\section{Authors' contributions}

HL.S.: analysis and interpretation of data, drafting the article; YH.L., YY.Q., RY. C. and LL.C.: acquisition of data; Y.H.: substantial contributions to conception and design, revising it critically for important intellectual content and final approval of the version to be published; XM.W.: revised manuscript editing. The author(s) read and approved the final manuscript.

\section{Funding}

The work was supported by Research Fund for Lin He's Academician Workstation of New Medicine and Clinical Translation (Grant No.18331201) and the Obstetrics and gynecology of combine traditional Chinese and Western medicine of Zhejiang Province (2017-XK-A42).

\section{Availability of data and materials}

The datasets used and/or analysed during the current study available from the corresponding author on reasonable request.

\section{Declarations}

\section{Ethics approval and consent to participate}

This study was performed in accordance with the Declaration of Helsinki and was approved by the Research Ethics Committee of the Second Affiliated Hospital of Wenzhou Medical University (approval number: L-2019-13). Informed consent was obtained from all individual participants included in the study.

\section{Consent for publication}

Patients signed informed consent regarding publishing their data.

\section{Competing interests}

The authors declare that they have no competing interests.

\section{Author details}

${ }^{1}$ Department of Obstetrics and Gynecology, the Second Affiliated Hospital of Wenzhou Medical University, 325027 Wenzhou, China. ${ }^{2}$ Department of Obstetrics and Gynecology, Wenzhou Central Hospital, 325000 Wenzhou, China. ${ }^{3}$ Department of Gynecology, Wenzhou People Hospital, 325000 Wenzhou, China.
Received: 8 November 2021 Accepted: 22 February 2022

Published online: 01 March 2022

\section{References}

1. Thorp JA, Dildy GA, Yeomans ER, Meyer BA, Parisi VM. Umbilical cord blood gas analysis at delivery. Am J Obstet Gynecol. 1996;175(3 Pt 1):517-22.

2. Armstrong $L$, Stenson BJ. Use of umbilical cord blood gas analysis in the assessment of the newborn. Arch Dis Child Fetal Neonatal Ed. 2007;92(6):F430-4.

3. Neilson JP. Umbilical cord blood gas analysis. BMJ. 2010;340:c1720.

4. Executive summary: Neonatal encephalopathy and neurologic outcome, second edition. Report of the American College of Obstetricians and Gynecologists'Task Force on Neonatal Encephalopathy. Obstet Gynecol. 2014;123(4):896-901.

5. Sabol BA, Caughey AB. Acidemia in neonates with a 5-minute Apgar score of 7 or greater - What are the outcomes? Am J Obstet Gynecol. 2016:215(4):486 e1-6.

6. Committee Opinion No. 684: Delayed Umbilical Cord Clamping After Birth. Obstet Gynecol. 2017;129(1):1.

7. Wiberg N, Kallen K, Olofsson P. Delayed umbilical cord clamping at birth has effects on arterial and venous blood gases and lactate concentrations. BJOG. 2008;115(6):697-703.

8. Valero J, Desantes D, Perales-Puchalt A, Rubio J, Diago Almela VJ, Perales A. Effect of delayed umbilical cord clamping on blood gas analysis. Eur J Obstet Gynecol Reprod Biol. 2012;162(1):21-3.

9. Giovannini N, Crippa BL, Denaro E, Raffaeli G, Cortesi V, Consonni D, et al. The effect of delayed umbilical cord clamping on cord blood gas analysis in vaginal and caesarean-delivered term newborns without fetal distress: a prospective observational study. BJOG. 2020;127(3):405-13.

10. De Paco C, Florido J, Garrido MC, Prados S, Navarrete L. Umbilical cord blood acid-base and gas analysis after early versus delayed cord clamping in neonates at term. Archives of Gynecology and Obstetrics. 2011;283(5):1011-4.

11. Andersson O, Hellstrom-Westas L, Andersson D, Clausen J, Domellof M. Effects of delayed compared with early umbilical cord clamping on maternal postpartum hemorrhage and cord blood gas sampling: a randomized trial. Acta Obstet Gynecol Scand. 2013;92(5):567-74.

12. De Paco C, Herrera J, Garcia C, Corbalan S, Arteaga A, Pertegal M, et al. Effects of delayed cord clamping on the third stage of labour, maternal haematological parameters and acid-base status in fetuses at term. Eur J Obstet Gynecol Reprod Biol. 2016;207:153-6.

13. Mitanchez D, Yzydorczyk C, Siddeek B, Boubred F, Benahmed M, Simeoni $U$. The offspring of the diabetic mother-short- and long-term implications. Best Pract Res Clin Obstet Gynaecol. 2015;29(2):256-69.

14. Reif P, Panzitt T, Moser F, Resch B, Haas J, Lang U. Short-term neonatal outcome in diabetic versus non-diabetic pregnancies complicated by non-reassuring foetal heart rate tracings. J Matern Fetal Neonatal Med. 2013;26(15):1500-5.

15. Anderberg E, Kallen K, Berntorp K. The impact of gestational diabetes mellitus on pregnancy outcome comparing different cut-off criteria for abnormal glucose tolerance. Acta Obstet Gynecol Scand. 2010;89(12):1532-7.

16. Muche AA, Olayemi OO, Gete YK. Gestational diabetes mellitus increased the risk of adverse neonatal outcomes: A prospective cohort study in Northwest Ethiopia. Midwifery. 2020;87:102713.

17. Riley RJ, Johnson JW. Collecting and analyzing cord blood gases. Clin Obstet Gynecol. 1993;36(1):13-23.

18. Roberts SW, Leveno KJ, Sidawi JE, Lucas MJ, Kelly MA. Fetal acidemia associated with regional anesthesia for elective cesarean delivery. Obstet Gynecol. 1995;85(1):79-83.

19. Robson SC, Boys RJ, Rodeck C, Morgan B. Maternal and fetal haemodynamic effects of spinal and extradural anaesthesia for elective caesarean section. Br J Anaesth. 1992;68(1):54-9.

20. Reynolds F, Seed PT. Anaesthesia for Caesarean section and neonatal acid-base status: a meta-analysis. Anaesthesia. 2005;60(7):636-53.

21. Xodo S, Xodo L, Berghella V. Delayed cord clamping and cord gas analysis at birth. Acta Obstet Gynecol Scand. 2018;97(1):7-12 
22. Mercer JS. Current best evidence: a review of the literature on umbilical cord clamping. J Midwifery Womens Health. 2001;46(6):402-14.

23. Bradley RJ, Brudenell JM, Nicolaides KH. Fetal acidosis and hyperlacticaemia diagnosed by cordocentesis in pregnancies complicated by maternal diabetes mellitus. Diabet Med. 1991;8(5):464-8.

24. Gluck L, Kulovich MV. Lecithin-sphingomyelin ratios in amniotic fluid in normal and abnormal pregnancy. Am J Obstet Gynecol. 1973;115(4):539-46.

25. Nelson SM, Freeman DJ, Sattar N, Lindsay RS. Erythrocytosis in offspring of mothers with Type 1 diabetes-are factors other than insulin critical determinants? Diabet Med. 2009;26(9):887-92.

26. Hopfeld-Fogel A, Kasirer Y, Mimouni FB, Hammerman C, Bin-Nun A. Neonatal Polycythemia and Hypoglycemia in Newborns: Are They Related? Am J Perinatol. 2021;38(9):930-4.

27. Rotshenker-Olshinka K, Shinwell ES, Juster-Reicher A, Rosin I, FlidelRimon O. Comparison of hematologic indices and markers of infection in umbilical cord and neonatal blood. J Matern Fetal Neonatal Med. 2014;27(6):625-8

28. Metzger BE, Persson B, Lowe LP, Dyer AR, Cruickshank JK, Deerochanawong C, et al. Hyperglycemia and adverse pregnancy outcome study: neonatal glycemia. Pediatrics. 2010;126(6):e1545-52.

\section{Publisher's Note}

Springer Nature remains neutral with regard to jurisdictional claims in published maps and institutional affiliations.

- fast, convenient online submission

- thorough peer review by experienced researchers in your field

- rapid publication on acceptance

- support for research data, including large and complex data types

- gold Open Access which fosters wider collaboration and increased citations

- maximum visibility for your research: over 100M website views per year

At $\mathrm{BMC}$, research is always in progress.

Learn more biomedcentral.com/submissions 